\title{
PERAMALAN UNTUK PERENCANAAN PRODUKSI STOP VALVE TIPE TX277S MENGGUNAKAN METODE PERAMALAN DERET WAKTU (TIME SERIES) DI PT. XYZ
}

\author{
Sudiman \\ Dosen Program Studi Teknik Industri, Fakultas Teknik, Universitas Pamulang, Banten \\ dosen01307@unpam.ac.id
}

\begin{abstract}
ABSTRAK
Untuk menghadapi kondisi persaingan industri manufaktur yang ketat perusahaan dituntut agar bisa memenuhi permintaan konsumen dengan cepat dan tepat tanpa mengesampingkan efisiensi. Peramalan akan suatu permintaan pasar sangatlah penting, karena sebagai acuan perencanaan produksi sebelum order diterima dari konsumen. Time series adalah suatu metode peramalan yang cukup banyak digunakan dalam peramalan permintaan. Model peramalan rata-rata bergerak menggunakan MA(4) didapat nilai sebesar 1361,72. Model peramalan rata-rata bergerak menggunakan MA(5) didapat nilai MAD sebesar 1440. Model peramalan pemulusan eksponensial dengan nilai ES $(\alpha=0,8)$ didapat nilai MAD yaitu 1158,3. Model peramalan pemulusan eksponensial dengan nilai ES $(\alpha=0,95)$ didapat nilai MAD yaitu 1248,75. Dari model peramalan yang digunakan, nilai MAD yang paling rendah adalah model ramalan pemulusan eksponensial menggunakan ES $(\alpha=0,8)$ yaitu 1158,3. Berdasarkan model peramalan pemulusan eksponensial dengan ES $(\alpha=0,8)$, maka dapat diperoleh nilai peramalan untuk bulan Mei 2020 yaitu 1158,3 .
\end{abstract}

Kata Kunci: Peramalan permintaan, Time Series, $M A D$

\section{PENDAHULUAN}

Perencanaan produksi adalah perencanaan produk jenis apa dan dalam jumlah berapa akan diproduksi oleh suatu perusahaan teetentu yang bersangkutan pada satu periode yang akan datang. Pada perencanaan produksi terdapat bagan perencanaan operasional di dalam perusahaan. Pada penyusunan perencanaan poduksi, perlu mempertimbangkan adanya optimasi produksi sehingga permintaan akan dapat dicapai dengan tingkat biaya yang paling rendah pada pelaksanaan proses produksinya. Namun sebelum melakukan perencanaan produksi, harus terlebih dahulu melakukan peramalan permintaan agar rencana produksi yang dibuat sesuai dengan atau mendekati permintaan pasar.

Suatu peramalan yang dibuat haruslah memenuhi kriteria tertentu sehingga peramalan tersebut bisa diterima dan dikatakan memiliki akurasi yang baik. Akurasi suatu peramalan dilihat dari tingkat errornya. Error digunakan sebagai acuan akurasi peramalan yang meliputi ME (mean error), MAE (mean absolute error), MPE (mean precentage error) MSE (mean square error), dan MAPE (mean absolute presentage error).

Hasil peramalan yang memiliki akurasi yang baik akan akan berpengaruh terhadap efektivitas produksi. Selain itu peramalan yang akurat akan memberikan kepuasan terhadap pelayan pelanggan.

\section{LANDASAN TEORI}

Peramalan permintaan atau sering disebut forecast demand (FD) adalah merupakan peramalan kuantitas permintaan pada sesuatu (barang atau jasa) dimasa yang akan datang. Vincent Gasperz menjelaskan didalam manajemen permintaan terdapat dua jenis permintaan yang meliputi permintaan bebas yang didefinisikan sebagai permintaan pada material, 
suku cadang atau produk yang bebas dan tidak terkait secara langsung dengan struktur bill of material (BOM) pada produk akhir atau item tertentu. Permintaan pada produk akhir, suku cadang atau produk yang sering digunakan sebagai percobaan.

Metode Peramalan adalah bagian dari ilmu statistika. Dimana salah satu metode peramalannya adalah deret waktu. Metode ini sering disebut sebagai metode deret waktu sebab memiliki karakteristik bahwa data yang akan dianalisis bersifat deret waktu. Periode waktu dari deret waktu bisa dalam tahunan, mingguan, bulanan, semester, kuartal dan lain sebagainya. Jenis pola pada data sangat penting untuk dikeahui sebab dapat berpengaruh terhadap hasil peramalan. Beberapa literatur menyebutkan, jika pola pada data cenderung akan berulang pada periode waktu yang akan datang. Identifikasi pola terhadap deret waktu juga bermanfaat untuk menentukan metode mana yang akan digunakan untuk menganalisis data tersebut.

Adaapun langkah-langkah dalam melakukan peralaman adalah sebagai berikut:

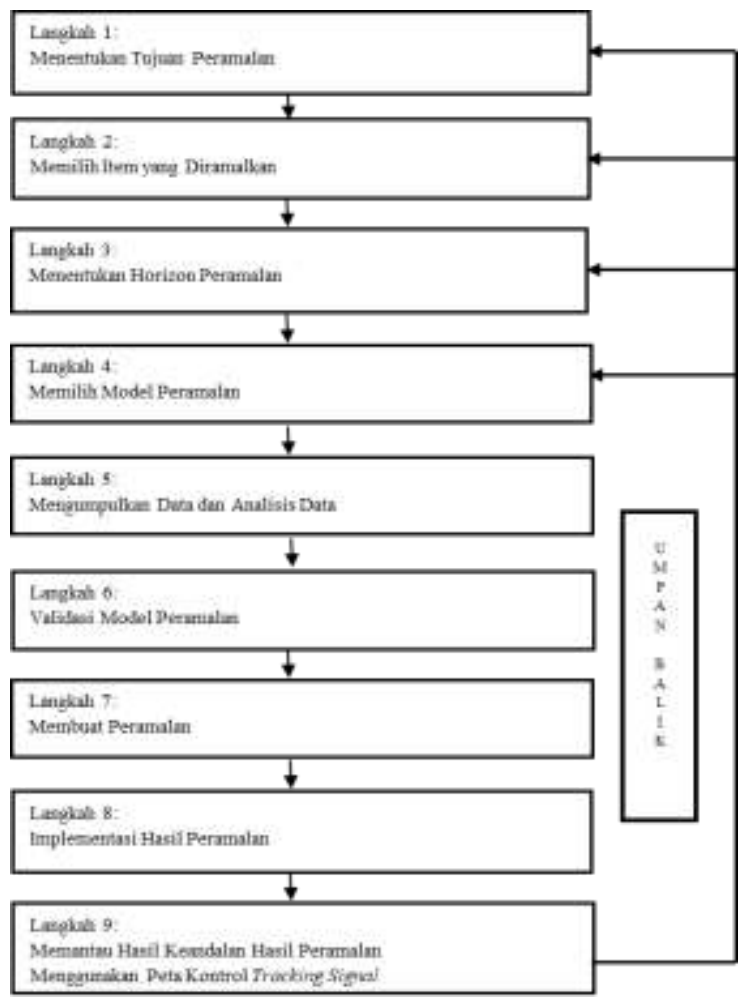

Gambar 1.1 Langkah-Langkah dalam Sistem Peramalan

\section{Jenis-jenis Metode Peramalan}

Pemilihan model-model peramalan akan bergantung pada pola pola data dan horizon waktu dari peramalan. Terdapat sejumlah model peramalan yang telah dikembangkan pada saat ini. Namun berdasarkan alasan data yang tersedia dan kemudahan model penggunaan dari model peramalan itu, hanya terdapat beberapa model umum yang sangat populer untuk diterapkan. Pada dasarnya model peramalan dapat dikategorikan menjadi dua kategori, yaitu Metode peramalan yang didasarkan atas penggunaan analisa hubungan antar variabel yang diperkirakan dengan variabel waktu deret berkala (time series). Metode yang termasuk pada jenis ini, yaitu metode pemulusan (smoothing), metode box Jenkins, metode proyeksi trend dengan regresi. Metode peramalan yang didasarkan atas penggunaan analisis pola hubungan antar variabel yang akan diperkirakan dengan variabel lain yang mempengaruhinya, yang bukan waktunya disebut Metode Korelasi atau sebab akibat (metode casual).

2. Metode Peramalan Deret Waktu (Time Series)

Pada Peramalan dengan analisis deret waktu, mendasarkan hasil ramalan sesuai susunan atas pola hubungan antara variabel yang akan dicari atau diramalkan menggunakan variabel waktu yang hanya satu-satunya variabel yang berpengaruh atau bebas. Peramalan dengan analisis deret waktu, merupakan usaha untuk mendapatkan pola deret data historis yang langkah selanjutnya untuk mengekstrapolasikan pola tersebut pada masa yang akan datang. Merupakan langkah yang cukup penting dalam menentukan metode analisis deret waktu dengan mempertimbangkan jenis pola yang terdapat dari data yang diamati. Komponenkomponen yang ada diidalam pola deret waktu dapat membangun pola data dan dikelompokkan dalam empat komponen utama, komponen tersebut adalah musiman, trend, siklikal dan yang terakhir komponen tak beraturan.

\section{Analisa Kesalahan Pada Peramalan}


Beberapa alat analisis kesalahan peramalan yang biasa digunakan adalah sebagai berikut:

\section{a. Mean Squared Error (MSE)}

Nilai Tengah Kesalahan Kuadrat (Mean Squared Error)

$\mathrm{MSE}=\frac{\sum_{t=1}^{n}\left(Y_{t}-\hat{Y}_{t}\right)}{n}$

b. Mean Absolute Percentage Error (MAPE)

Nilai Tengah Kesalahan Presentase Absolut (Mean Absolute Percentage Error)

$$
\text { MAPE }=\frac{\sum_{t=1}^{n} \frac{\left|Y_{t}-\widehat{Y}_{t}\right|}{Y_{t}}}{n}
$$

\section{Validasi Peramalan}

Hal yang harus dilakukan yaitu dengan menghitung tracking signal untuk setiap nilai ramalan yang akan muncul.Tracking signal merupakan salah satu bentuk ukuran sebagaimana agar baiknya suatu ramalan dapat memperkirakan nilai-nilai aktual. Suatu ramalan dapat diperbarui setiap minggu, bulan atau bahkan triwulan sehingga data permintaan dapat dibandingkan dengan nilai-nilai hasil ramalan. Tracking signal juga dapat dihitung sebagai hasil running sum of forcast error (RSFE) dibagi oleh mean absolute deviation (MAD), seperti berikut ini:

Tracking Signal $=\frac{R S F E}{M A D}$

Dimana:

$\mathrm{MAD}=\frac{\sum(\text { absolut dari forcast error })}{n}$

$\mathrm{n}=$ banyaknya periode sebuah data

Oliver Wight dan George Plossl, keduanya ahli dalam pengendalian persediaan, mereka menyarankan agar batas tracking signal bisa menggunakan nilai maksimum \pm 4 MAD (untuk persediaan volume maksimum) dan \pm 8 MAD (untuk produk dengan volume minimum). Peramal biasanya menyatakan rentang nilai MAD yang lebih rendah. 1 MAD rata-rata sama dengan 0,8 deviasi standarnya, sehingga $\pm 2 \mathrm{MAD}= \pm 1,6$ deviasi standarnya, \pm 3 MAD $= \pm 2,4$ deviasi standarnya, dan \pm 4 MAD $= \pm 3,2$ deviasi standarnya. Ini menyatakan bahwa pada peramalan yang berada "dalam pengawasan", $89 \%$ kesalahan yang diharapkan dalam \pm 2 MAD, $98 \%$ berada pada \pm 3 MAD, atau 99,9\% dalam \pm 4 MAD.

\section{METODOLOGI PENELITIAN}

Metode yang digunakan adalah menggunakan metode time saries peramalan yang meliputi ME (mean error), MAE (mean absolute error), MPE (mean precentage error) MSE (mean square error), dan MAPE (mean absolute presentage error).

\section{PEMBAHASAN}

\subsection{Pengolahan Data}

Pengolahan data merupakan prioritas utama dalam melakukan penelitian, adapun langkah-langkah yang harus dilakukan dalam mengolah data khususnya dalam manajemen permintaan adalah sebagai berikut:

1. Identifikasi dari pola historis data aktual.

2. Pilihlah metode peramalan yang tepat dengan pola historis dari data aktual permintaan yang ada.

3. Lakukan analisis data berdasarkan motode peramalan yang telah dipilih.

4. Pilih metode peramalan yang sesuai berdasarkan MAD (Mean Absolute Deviation).

5. Periksa keandalan dari model peramalan yang dipilih sesuai peta kontrol tracking signal.

\subsection{Pola Historis dan Aktual Permintaan}

Data yang diperoleh dilapangan adalah merupakan data aktual yang akan diidentifikasi pola historisnya. Data-data yang diperoleh dilapangan adalah sebagai berikut:

Tabel 4.1 Data Aktual Permintaan Shower Spray Type THX20MCR 


\begin{tabular}{|l|r|r|}
\hline Bulan/Tahun & Indeks Waktu (t) & Permintaan Aktual (A) \\
\hline Mei 2019 & 1 & 3500 \\
Juni 2019 & 2 & 2725 \\
Juli 2019 & 3 & 2825 \\
Agustus 2019 & 4 & 4050 \\
September 2019 & 5 & 3900 \\
Oktober 2019 & 6 & 6300 \\
Nopember 2019 & 7 & 3300 \\
Desember 2019 & 8 & 3750 \\
Januari 2020 & 9 & 4950 \\
Februari 2020 & 10 & 3075 \\
Maret 2020 & 11 & 750 \\
April 2020 & 12 & 2550 \\
\hline
\end{tabular}

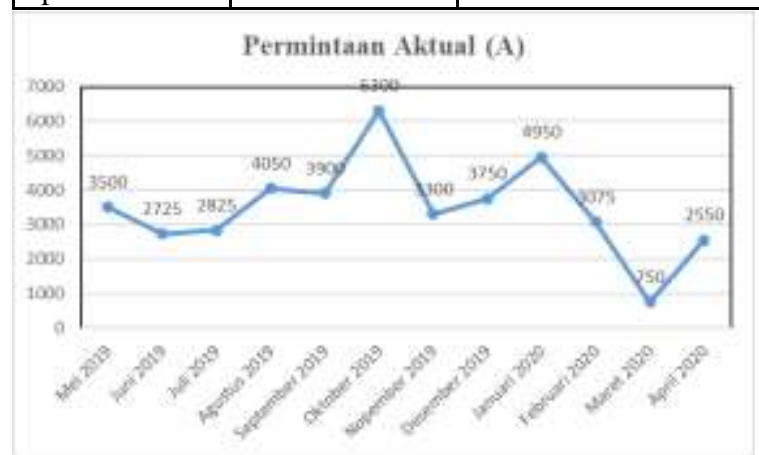

Gambar 4.1 Permintaan Aktual Shower Spray Type THX20MCR

\subsection{Peramalan Model Rerata Bergerak (Moving Average)}

Dalam peramalan model rerata bergerak dapat mengunakan periode waktu periode empat bulanan dan lima bulanan.

Tabel 4.2 Data Aktual Permintaan Shower Spray Type THX20MCR

\begin{tabular}{|l|c|c|c|c|}
\hline \multirow{2}{*}{ Bulan } & Indeks (t) & $\begin{array}{c}\text { Permintaa } \\
\mathbf{n}(\mathbf{A})\end{array}$ & Ramalan & Ramalan \\
\cline { 4 - 5 } & & & MA (4) & MA (5) \\
(F,MA,5) & (F,MA,5) \\
\hline Mei 2019 & 1 & 3500 & - & - \\
\hline Juni 2019 & 2 & 2725 & - & - \\
\hline Juli 2019 & 3 & 2825 & - & - \\
\hline Agustus 2019 & 4 & 4050 & - & - \\
\hline September 2019 & 5 & 3900 & 3275 & - \\
\hline Oktober 2019 & 6 & 6300 & 3375 & 3400 \\
\hline November 2019 & 7 & 3300 & 4268,75 & 3960 \\
\hline Desember 2019 & 8 & 3750 & 4387,5 & 4075 \\
\hline Januari 2020 & 9 & 4950 & 4312,5 & 4260 \\
\hline Februari 2020 & 10 & 3075 & 4575 & 4440 \\
\hline Maret 2020 & 11 & 750 & 3768,75 & 4275 \\
\hline April 2020 & 12 & 2550 & 3131,25 & 3165 \\
\hline Mei 2020 & 13 & $? ? ?$ & 2831,25 & 3015 \\
\hline
\end{tabular}

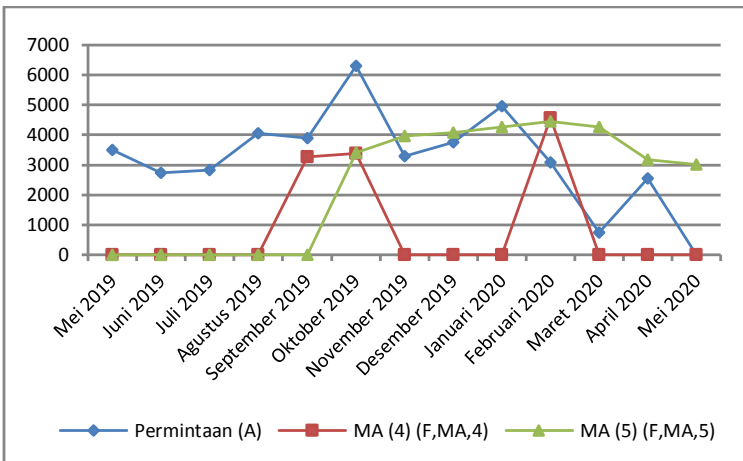

Gambar 4.2 Data Aktual Peramalan MA(4) dan Peramalan(5)

\subsection{Tracking Signal Model Rata-rata \\ Bergerak (Moving Averages)}

Dari data di tabel 4.1 dapat dihitung tracking signalnya, yaitu sebagai berikut:

1. Tracking Signal Model Rerata Bergerak empat bulan, MA(4)

Tabel 4.3 Tracking Signal Model Ramalan Rerata Bergerak (Moving Average), MA(4)

\begin{tabular}{|c|r|r|r|r|r|r|r|r|}
\hline Periode & Forecast & Aktual & Error & RSFE & Absolut & Kumulatif & MAD & Tracking \\
\hline (n) & F & A & E=A-F & & Error & Absolut & & Signal \\
\hline & & & & & & Error & & \\
\hline 1 & 3275 & 3900 & 625 & 625 & 625 & 625 & 625 & 1,00 \\
\hline 2 & 3375 & 6300 & 2925 & 3550 & 2925 & 3550 & 1775 & 2,00 \\
\hline 3 & 4268,75 & 3300 & $-968,75$ & 2581,25 & 968,75 & 4518,75 & 1506,25 & 1,71 \\
\hline 4 & 4387,5 & 3750 & $-637,5$ & 1943,75 & 637,5 & 5156,25 & 1289,06 & 1,51 \\
\hline 5 & 4312,5 & 4950 & 637,5 & 443,75 & 637,5 & 5793,75 & 1158,75 & 0,38 \\
\hline 6 & 4575 & 3075 & -1500 & $-1056,25$ & 1500 & 7293,75 & 1215,63 & $-0,87$ \\
\hline 7 & 3768,8 & 750 & $-3018,75$ & -4075 & 3018,75 & 10312,5 & 1473,21 & $-2,77$ \\
\hline 8 & 3131,3 & 2550 & $-581,25$ & $-4656,25$ & 581,25 & 10893,75 & 1361,72 & $-3,42$ \\
\hline
\end{tabular}

Berdasarkan tabel 4.3 diatas, maka dapat dihitung nilai MAD dan Tracking Signalnya, seperti berikut:

$$
\begin{aligned}
& \text { MAD }=\frac{\sum \text { (absolut dari forecast error) }}{n} \\
& =\frac{10893,75}{8}=1361,72
\end{aligned}
$$

Tracking Signal $=\frac{R S F E}{M A D}=\frac{-4656,25}{1361,72}=-3,42$

Dari tabel 4.3 dapat dilihat bahwa nilai hasil tracking signal yang berada pada batas-batas yang masih bisa diterima (maksimum \pm 4 ), yang 
pada nilai-nilai tracking signal itu bergerak mulai dari +2 samapai $-3,42$. Hal ini dapat diartikan bahwa akurasi pada model peramalan tersebut masih pada posisi didalam batas-batas kendali tracking signal (maksimum \pm 4 ).

Agar memperjelas, maka dapat dilihat pada gambar 3.3 yang menunjukkan grafik pergerakan nilai-nilai dari tracking signal.

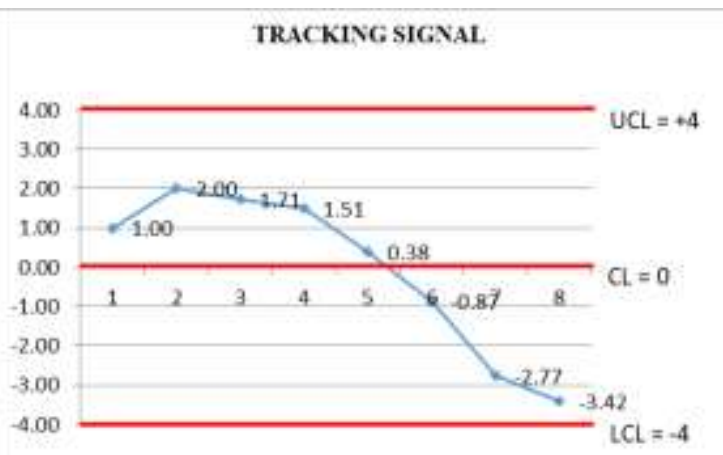

Gambar 4.3 Peta Hasil Kontrol Tracking Signal Metode Peramalan Rerata Bergerak (Moving Averages), MA (4)

2. Tracking Signal Model Rata-rata Bergerak Selama 5 bulan, MA (5)

Tabel 4.4 Tracking Signal Model Ramalan Rerata Bergerak (Moving Average), MA(5)

\begin{tabular}{|c|c|c|c|c|c|c|c|c|}
\hline $\begin{array}{c}\text { Peri } \\
\text { ode }\end{array}$ & \begin{tabular}{|c} 
Forec \\
ast,
\end{tabular} & $\begin{array}{c}\text { Aktu } \\
\text { al, }\end{array}$ & Error, & RSFE & $\begin{array}{c}\text { Absol } \\
\text { ut }\end{array}$ & $\begin{array}{l}\text { Kumulati } \\
\text { f Absolut }\end{array}$ & MAD & $\begin{array}{c}\text { Tracking } \\
\text { Signal }\end{array}$ \\
\hline (n) & F & A & $E=A-F$ & & & Error & & \\
\hline 1 & 6300 & 3400 & -2900 & -2900 & 290 & 2900 & 2900 & $-1,00$ \\
\hline 2 & 3300 & 3960 & 660 & -2240 & 66 & 3560 & 1780 & $-1,26$ \\
\hline 3 & 3750 & 4075 & 325 & -1915 & 32 & 3885 & 1295 & $-1,48$ \\
\hline 4 & 4950 & 4260 & -690 & -2605 & 69 & 4575 & 143,75 & $-2,28$ \\
\hline 5 & 3075 & 4440 & 1365 & -1240 & 136 & 5940 & 1188 & $-1,04$ \\
\hline 6 & 750 & 4275 & 3525 & 2285 & 352 & 9465 & 1577,5 & 1,45 \\
\hline 7 & 2550 & 3165 & 615 & 2900 & 61. & 10080 & 1440 & 2,01 \\
\hline
\end{tabular}

Berdasarkan tabel 4.4 diatas, maka dapat dihitung nilai MAD dan Tracking Signalnya, seperti berikut ini:

$$
\begin{aligned}
& \text { MAD }=\frac{\left.\sum \text { (absolut dari forecast error }\right)}{n}=\frac{10080}{7} \\
& =1440
\end{aligned}
$$

$$
\text { Tracking Signal }=\frac{R S F E}{M A D}=\frac{2900}{1440}=2,01
$$

\subsection{Peramalan Model Pemulusan Eksponensial (Exponential Smoothing)}

Dalam melihat grafik pada gambar 4.1 yang menunjukkan fluktuasi permintaan aktual yang tidak stabil tiap waktunya, maka nilai $\alpha$ yang dipilih adalah nilai $\alpha$ yang mendekati satu. Dalam hal ini akan mencoba dengan menggunakan nilai $\alpha=0,8$ dan juga akan menggunakan nilai $\alpha=0,95$.

Hasil perhitungan dengan model pemulusan ekspomensial (exponential smoothing) untuk meramalkan Februari 2013 adalah sebagai berikut:

Tabel 4.5 Hasil Ramalan Model Exponential Smoothing

\begin{tabular}{|l|c|c|r|r|}
\hline \multicolumn{1}{|c|}{ Bulan } & $\begin{array}{c}\text { Indeks } \\
(\mathbf{t})\end{array}$ & $\begin{array}{c}\text { Permintaan } \\
(\mathbf{A})\end{array}$ & $\begin{array}{c}\text { Ramalan Berdasarkan } \\
\mathbf{E S}(\boldsymbol{\alpha}=\mathbf{0 , 8}),(\mathbf{F}, \mathbf{E S} \boldsymbol{\alpha}=\mathbf{0 , 8})\end{array}$ & $\begin{array}{c}\text { Ramalan Berdasarkan } \\
\mathbf{E S}(\boldsymbol{\alpha}=\mathbf{0 , 9 5}),(\mathbf{F}, \mathbf{E S} \boldsymbol{\alpha}=\mathbf{0 , 9 5})\end{array}$ \\
\hline & & & 3473 & 3473 \\
Mei 2019 & 1 & 3500 & & \\
Juni 2019 & 2 & 2725 & $3473+0,8(3500-3473)=3495$ & $3473+0,95(3500-3473)=3499$ \\
Juli 2019 & 3 & 2825 & $3495+0,8(2725-3495)=2879$ & $3499+0,95(2725-3499)=2764$ \\
Agustus 2019 & 4 & 4050 & $2879+0,8(2825-2879)=2836$ & $2764+0,95(2825-2764)=2823$ \\
September 2019 & 5 & 3900 & $2836+0,8(4050-2836)=3807$ & $2823+0,95(4050-2823)=3988$ \\
Oktober 2019 & 6 & 6300 & $3807+0,8(3900-3807)=3881$ & $3988+0,95(3900-3988)=3904$ \\
Nopember 2019 & 7 & 3300 & $3881+0,8(6300-3881)=5816$ & $3904+0,95(6300-3904)=6180$ \\
Desember 2019 & 8 & 3750 & $5816+0,8(3300-5816)=3803$ & $6180+0,95(3300-6180)=3444$ \\
Januari 2020 & 9 & 4950 & $3803+0,8(3750-3803)=3761$ & $3444+0,95(3750-3444)=3734$ \\
Februari 2020 & 10 & 3075 & $3761+0,8(4950-3761)=4712$ & $3734+0,95(4950-3734)=4899$ \\
Maret 2020 & 11 & 750 & $4712+0,8(3075-4712)=3402$ & $4889+0,95(3075-4889)=3166$ \\
April 2020 & 12 & 2550 & $3402+0,8(750-3402)=1280$ & $3166+0,95(750-3166)=870$ \\
Mei 2020 & 13 & $? ? ?$ & $1280+0,8(2550-1280)=2296$ & $870+0,95(2550-870)=2466$ \\
\hline
\end{tabular}

Pada model peramalan pemulusan eksponesial dengan menggunakan nilai $\alpha=0,8$ maka didapatkan perkiraan perencanaan produksi shower spray type THX20MCR untuk bulan Mei 2020 adalah sebanyak 2296 pcs. Sementara itu dengan menggunakan metode Ramalan eksponensial yang menggunakan nilai $\alpha=0,95$ didapatkan perkiraan perencanaan produksi shower spray type THX20MCR untuk bulan Mei 2020 adalah sebanyak 2446 pcs.

Dari tabel diatas dapat digambarkan oleh gambar 4.4 dibawah ini dan dapat dilihat perbandingan antara permintaan aktual dan ramalan pada permintaan berdasarkan model pemulusan eksponensial (exponential smooothing) dengan nilai $\alpha=0,8$ dan $\alpha=0,95$. 
diterima karena berada diantara angka (minimum -4) dan angka (maksimum +4). Yang mana nilai hasil tracking signal tersebut bergerak mulai dari nilai $+3,8$ sampai $-2,8$. Hal tersebut artinya bahwa akurasi dari model ramalan exponential smoothing ES $(\alpha=0,8)$ bisa diandalkan sebab masih berada dalam batas kendali tracking signal $( \pm 4)$. Pada tracking signal yang sudah baik mempunyai RSFE yang relatif rendah sehingga pusat tracking signal akan mendekati nilai nol(0). Hal tersebut sudah bisa dipenuhi oleh metode peramalan exponential smoothing ES $(\alpha=0,8)$ dan bisa dilihat pada gambar 3.5 sebagai berikut:

Gambar 4.4 Data Aktual Peramalan Pemulusan Eksponensial (Exponential Smoothing) ES ( $\alpha=$ $0,8)$ dan ES $(\alpha=0,95)$

\subsection{Tracking Signal Model Pemulusan Eksponensial}

Tracking signal digunakan untuk menghitung keandalan suatu metode peramalan. Dari data tabel 4.5 dapat dihitung tracking signalnya sebagai berikut:

1. Peramalan Exponential Smothing $(\alpha=0,8)$

Tabel 4.6 Tracking Signal Exponential Smoothing, $E S(\alpha=0,8)$

\begin{tabular}{|c|r|r|r|r|r|r|r|r|}
\hline $\begin{array}{c}\text { Periode } \\
\text { (n) }\end{array}$ & Forecast, & $\begin{array}{c}\text { Aktual, } \\
\text { A }\end{array}$ & $\begin{array}{c}\text { Error, } \\
\text { E= A-F }\end{array}$ & RSFE & $\begin{array}{c}\text { Absolut } \\
\text { Error }\end{array}$ & $\begin{array}{c}\text { Kumulatif } \\
\text { Absolut Error }\end{array}$ & MAD & $\begin{array}{c}\text { Tracking } \\
\text { Signal }\end{array}$ \\
\hline 1 & 3473 & 3500 & 27 & 27 & 27 & 27 & 27 & 1,0 \\
2 & 3495 & 2725 & -770 & -743 & 770 & 797 & 398,5 & $-1,9$ \\
3 & 2879 & 2825 & -54 & -797 & 54 & 851 & 283,7 & $-2,8$ \\
4 & 2836 & 4050 & 1214 & 417 & 1214 & 2065 & 516,3 & 0,8 \\
5 & 3807 & 3900 & 93 & 510 & 93 & 2158 & 431,6 & 1,2 \\
6 & 3881 & 6300 & 2419 & 2929 & 2419 & 4577 & 762,8 & 3,8 \\
7 & 5816 & 3300 & -2516 & 413 & 2516 & 7093 & 1013,3 & 0,4 \\
8 & 3808 & 3750 & -58 & 355 & 58 & 7151 & 893,9 & 0,4 \\
9 & 3761 & 4950 & 1189 & 1544 & 1189 & 8340 & 926,7 & 1,7 \\
10 & 4712 & 3075 & -1637 & -93 & 1637 & 9977 & 997,7 & $-0,1$ \\
11 & 3402 & 750 & -2652 & -2745 & 2652 & 12629 & 1148,1 & $-2,4$ \\
12 & 1280 & 2550 & 1270 & -1475 & 1270 & 13899 & 1158,3 & $-1,3$ \\
\hline
\end{tabular}

Berdasarkan tabel 4.

6 diatas, maka dapat dihitung nilai MAD dan juga dapat dihitung tracking signalnya, seperti berikut:

$\mathrm{MAD}=\frac{\left.\sum \text { (absolut dari forecast error }\right)}{\mathrm{n}}=\frac{13899}{12}$ $=1158,3$

Tracking Signal $=\frac{R S F E}{M A D}=\frac{-1475}{1158,3}=-1,3$

Berdasarkan hasil perhitungan tracking signal untuk metode pemulusan eksponensial (exponential smoothing), ES $(\alpha=0,8)$ yaitu -1.3 , berada antara batas-batas yang masih dapat

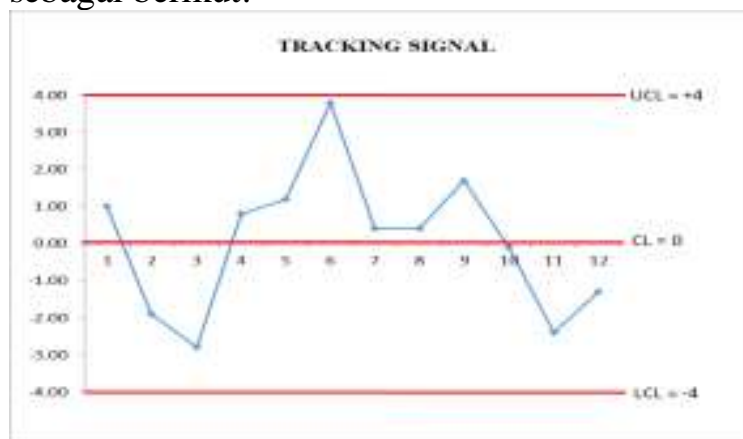

Gambar 4.5 Peta Kontrol Tracking Signal Model Exponential Smoothing $(\alpha=0,8)$

2. Peramalan Exponential Smothing $(\alpha=0,95)$

Tabel 3.7 Tracking Signal Exponential Smoothing, ES $(\alpha=0,95)$

\begin{tabular}{|c|r|r|r|r|r|r|r|r|}
\hline $\begin{array}{c}\text { Periode } \\
(\mathbf{n})\end{array}$ & $\begin{array}{r}\text { Forecast, } \\
\text { F }\end{array}$ & $\begin{array}{r}\text { Aktual, } \\
\text { A }\end{array}$ & $\begin{array}{c}\text { Error, } \\
\text { E= A-F }\end{array}$ & RSFE & $\begin{array}{c}\text { Absolut } \\
\text { Error }\end{array}$ & $\begin{array}{c}\text { Kumulatif } \\
\text { Absolut } \\
\text { Error }\end{array}$ & MAD & $\begin{array}{c}\text { Tracking } \\
\text { Signal }\end{array}$ \\
\hline 1 & 3473 & 3500 & 27 & 27 & 27 & 27 & 27,0 & 1,00 \\
2 & 3499 & 2725 & -774 & -747 & 774 & 801 & 400,5 & $-1,87$ \\
3 & 2764 & 2825 & 61 & -686 & 61 & 862 & 287,3 & $-2,39$ \\
4 & 2823 & 4050 & 1227 & 541 & 1227 & 2089 & 522,3 & 1,04 \\
5 & 3988 & 3900 & -88 & 453 & 88 & 2177 & 435,4 & 1,04 \\
6 & 3904 & 6300 & 2396 & 2849 & 2396 & 4573 & 762,2 & 3,74 \\
7 & 6180 & 3300 & -2880 & -31 & 2880 & 7453 & 1064,7 & $-0,03$ \\
8 & 3444 & 3750 & 306 & 275 & 306 & 7759 & 969,9 & 0,28 \\
9 & 3734 & 4950 & 1216 & 1491 & 1216 & 8975 & 997,2 & 1,50 \\
10 & 4899 & 3075 & -1824 & -333 & 1824 & 10799 & 1079,9 & $-0,31$ \\
11 & 3166 & 750 & -2416 & -2749 & 2416 & 13215 & 1201,4 & $-2,29$ \\
12 & 870 & 2550 & 1680 & -1069 & 1680 & 14895 & 1241,3 & $-0,86$ \\
\hline
\end{tabular}

Berdasarkan tabel 3.7 diatas, maka dapat dihitung nilai MAD dan juga dapat dihitung tracking signalnya, sepertii berikut:

$\begin{aligned} \text { MAD } & =\frac{\left.\sum \text { (absolut dari forecast error }\right)}{\mathrm{n}}=\frac{14895}{12} \\ & =1248,75\end{aligned}$

Tracking Signal $=\frac{R S F E}{M A D}=\frac{-1069}{1248,75}=-0,86$ 
Berdasarkan hasil perhitungan tracking signal untuk metode pemulusan eksponensial (exponential smoothing), ES $(\alpha=0,95)$ yaitu 0.86 , berada dalam batas-batas yang dapat diterima karena berada diantara angka (minimum -4) dan angka (maksimum +4). Yang mana nilai hasil tracking signal tersebut bergerak mulai dari nilai $+3,74$ sampai $-2,39$. Menunjukkan akurasi dari model peramalan exponential smoothing ES $(\alpha=0,95)$ bisa diandalkan sebab masih dalam batas kendali pada tracking signal $( \pm 4)$. Pada tracking signal yang relative baik mempunyai RSFE yang cukup rendah, sehingga pusat tracking signal mendekati nilai nol(0). Hal tersebut sudah dapat dipenuhi oleh metode peramalan exponential smoothing ES $(\alpha=0,95)$ dan bisa dilihat pada gambar 3.6 sebagai berikut:

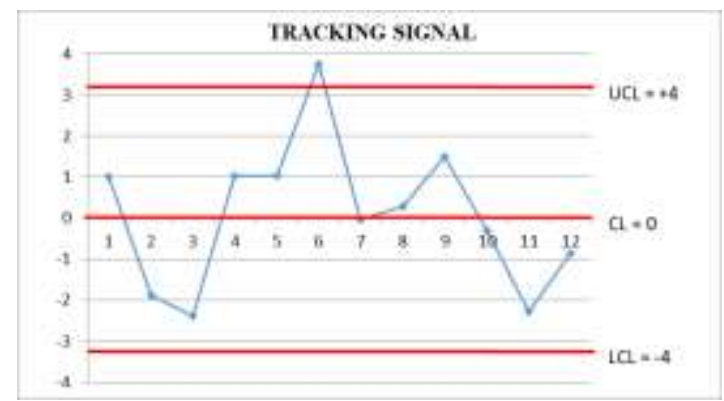

Gambar 3.6 Peta Kontrol Tracking Signal Metode Exponential Smoothing $(\alpha=0,95)$

\section{KESIMPULAN}

Dari analisis yang telah dilaksanakan tentang perencanaan produksi dengan teknik ramalan time series dalam proses perencanaan produksi shower spray type THX20MCR di PT. XYZ, dapat disimpulkan sebagai berikut:

1. Hasil dari metode peramalan time series, seperti berikut:

a. Model peramalan rerata bergerak (moving average) menggunakan MA(4) didapat nilai MAD (Mean Absolute Deviation) yaitu 1361,72.

b. Model peramalan rerata bergerak (moving average) menggunakan MA(5) didapat nilai MAD (Mean Absolute Deviation) yaitu 1440.

c. Model peramalan pemulusan eksponensial (exponential smoothing) menggunakan nilai ES $(\alpha=0,8)$ didapat nilai MAD (Mean Absolute Deviation) yaitu 1158,3.

d. Model peramalan pemulusan eksponensial (exponential smoothing) diperoleh nilai ES $(\alpha=0,95)$ dengan nilai MAD (Mean Absolute Deviation) sebesar 1248,75.

2. Dari model ramalan yang telah digunakan, maka nilai MAD (Mean Absolute Deviation) yang terrendah adalah dengan model ramalan pemulusan eksponensial (exponential smoothing) menggunakan ES $(\alpha=0,8)$ yaitu 1158,3 .

3. Berdasarkan metode peramalan pemulusan eksponensial (exponential smoothing) menggunakan ES $(\alpha=0,8)$, maka dapat diperoleh nilai peramalan untuk bulan Februari 2013 yaitu 1158,3 (dibulatkan menjadi 1158).

\section{DAFTAR PUSTAKA}

Alfatiyah, R. (2017). Perencanaan Produksi Minyak Telon Ukuran 100 Ml Dengan Metode Time Series Di PT. MERPATI MAHARDIKA. Teknik INDUSTRI, 9(25).

Anik, dkk. 2016. Analisis Peramalan Penjualan Untuk Menentukan Rencana Produksi Pada Ud Rifa'i. Jurnal Ekonomi dan Bisnis GROWTH Vol. 14, No. 2, November $2016: 17-30$

Armstrong, J. and Fildes, R. 2006. Making Progress in Forecasting. International Journal of Forecasting, 22, 433-411

Arsyad, Lincolin. 2009. Prakiraan Bisnis Edisi Pertama. Yogyakarta: Badan Penelitian Fakultas Ekonomi-Yogyakarta.

Awwaliyah, N. 2013. Penerapan Metode Double Exponential smoothing dalam Meramalkan Jumlah Penderita Kusta di Kabupaten Pasuruan Tahun 2014. Skripsi. Surabaya, Universitas Airlangga

Gaspersz, Vincet. 2005. Production Planning and Inventory Control, Gramedia Pustaka Utama, Jakarta.

Heizer, Jay and Baryy Render. 2017. Operations Management and Sustainability Supply Chain Management 12th Edition).

Pearson Education. Hartanti, D. Oki. 2014. Perbandingan Hasil Prakiraan dengan Metode Double Exponential smoothing Holt dan Metode Jaringan Syaraf Tiruan. 
$p-I S S N: 2620-5793$

$e-I S S N: 2685-6123$

Universitas Airlangga: Jurnal Biometrika dan Kependudukan, Vol. 3 No. 2, Desember 2014

Ihsan, G. Miftah, Kholil, M. 2014. Analisa Prakiraan permintaan Produk Pipa PVC
AW1/2" SC 4M pada PT. WDJ. Jakarta: Jurnal Integra Vol. 4, No. 1, Juni 2014 